\title{
Research and Application of Ankle Morphological Changes and Classification
}

\author{
Chunqiang Zhang ${ }^{1^{*}}$, Xiaomin $\mathrm{Ji}^{1}$, Yanmin Xue ${ }^{1}$ and Gang $\mathrm{Hu}^{1}$ \\ ${ }^{1}$ Xi'an University of Technology, Xi'an, Shaanxi, 710054, China
}

\begin{abstract}
Because of the motion of ankle joint, the surface morphological changes. The relevant products including ankle brace, ankle boot, etc. with both important protective effect on ankle and comfort should be designed to match the ankle varies states. The samples data with $15^{\circ}$ plantar flexion, $40^{\circ}$ dorsiflexion and neutral position of lower $\operatorname{limbs}(\mathrm{N}=105)$ were scanned. This study analyzed the feature of the ankle morphological changes and divided it into four parts: anterolateral (I), posterolateral (II), posteromedial (III) and anteromedial (IV). The anterior and posterior parts had large contraction and expansion during plantar flexion and dorsiflexion motions. The medial and lateral parts of ankle shape were asymmetric, but had equal skin areas. Therefore, the area of the entire ankle surface remained almost the same when morphological changes. We unified the data of the models and measured the distances of characteristic points. According to the main dimensions, the ankles were classified into 17 groups. The rigid brace design was taken as an example to fit mass ankles. It showed a great statistical comfort degree in total by the user experience and evaluation. The method combining with features of ankle morphological changes and shape classification was proved to be effective for the ankle related products design to fit mass ankles.
\end{abstract}

\section{Introduction}

The ankle joint complex bears a force of approximately five times body weight during stance in normal walking, and up to thirteen times body weight during activities such as running[1]. In sports, ankle ligament injury is occurred frequently[2]. Therefore, it is very important for the design of ankle related products to be of protectiveness and comfort. At present, for the design of many products and the purpose of obtaining the parameters matching with human body, images technology is used to obtain the data of the relevant parts in human body. The shapes classification is very effective as the main reference method of product design. Various kinds of images technology are widely used in different research fields. 3D internal images of a patient body, X-rays, computed-tomography, (CT) scanners, Ultrasound and Magnetic resonance imaging (MRI) are commonly used to measure body shape and size[3]. For example, the morphometry of the ankle joint including the radius, arc length, width of the trochlea tali and the tibial was evaluated by CT scanning database[4]. For the product design based on human body dimensions, $\mathrm{Yu}$ et al.[5] measured and analyzed the ear canal of human body through the technology of CT scanning and digital measurement, so as to complete the style design of hearing aid and noise reduction earplug. Harih et al.[6] made statistical analysis on the three-dimensional hand shape in the grip state through the MRI technology, and established the design method of reverse tool handle shape through the static digital hand model, which greatly improved the user's comfort during operation. With the advent of 3D scanners, which are safe and convenient to use to measure a person's body shape, size, texture, colour and skin-surface area accurately, a new application is emerging, i.e. 3D scanning has a high capability of capturing 3D measurement[7]. Ji et al.[8] obtained the data of concha cavity by $3 \mathrm{D}$ scanning technology, and classified the shapes of concha cavity, which was used in the earphone modeling design. Many studies have reported the design of human foot related products. Using 3D foot-scan database for statistical foot shape analysis that can be applied to improve the comfort degrees of insole and footwear[9-13]. However, for the ankle, most studies are focus on the ankle joint including kinematics, biomechanics, etc. But few studies reported the external shape of ankle. The relevant products with both important protective effect on ankle and comfort, such as ankle brace, ankle boot, short boot, and long boot, which involve the shape and size of the ankle when they are designed. In this study, 3D scanning data is used to obtain the characteristic points and distances of ankle. The features of ankle morphological changes are analyzed and the key characteristic distance clustering method is used to classify ankle shape. The rigid brace design will be taken as an example to fit mass ankles.

\footnotetext{
*Corresponding author's e-mail: 12130137@qq.com
} 


\section{Materials and Methods}

\subsection{Participants and acquisition of 3D scanning data}

The morphology of ankle involved the foot and lower leg. The data of lower limber with $15^{\circ}$ plantar flexion (Pf), $40^{\circ}$ dorsiflexion (Df) and standing state (St) of lower limbs from participants $(\mathrm{N}=105,52$ males and 53 females) were scanned. The lower limber surface point cloud data was obtained using the Creaform Go!SCAN 3D scanner with an accuracy of $0.1 \mathrm{~mm}$. The missing point were repaired by ImageWare software platform. Approximate data can be obtained for the left lower limb by mirroring.

\subsection{Characteristic points and distances}

From the scanning data, it can be found that there are two main characteristic points for the morphological changes of ankle in the foot part. One is the instep and the other is the heel. Point A is defined as the starting point of morphological change of instep, while point B is defined as the starting point of morphological change of heel.
The coordinates of the two points are A and B, a plane that passes through these two points and parallels the coronal axis of the ankle. The points less than the given threshold (1mm) from the plane can be obtained. These points constituted a closed curve is of girth as the dividing line between the foot and ankle, denoted as line FL. The morphological changes of ankle in the lower leg part are mainly under the minimum girth (LL). Point $\mathrm{E}$ is defined as the endpoint on the anterior side, while point $\mathrm{F}$ as the endpoint on the posterior side. Point $\mathrm{C}$ is defined as the protrusion point of the medial malleolus of tibia, point $\mathrm{D}$ as the protrusion point of the lateral malleolus of fibula, and point $\mathrm{O}$ as the midpoint of line $\mathrm{CD}$. There is a plane that goes through the points $\mathrm{C}$ and $\mathrm{D}$ and is perpendicular to the line $\mathrm{AB}$. The plane intersects with line $\mathrm{AB}$ and girth $\mathrm{FL}$ at points $\mathrm{P}, \mathrm{G}$, and J. Another plane is perpendicular to the line $\mathrm{EF}$, and intersects with line EF and girth LL at points $\mathrm{Q}, \mathrm{H}$, and $\mathrm{K}$ respectively. Points $\mathrm{H}$ and $\mathrm{K}$ represent the inside and outside width position characteristic points of girth LL, and points $G$ and $\mathrm{J}$ respectively represent that of girth FL. Figure 1 shows the characteristic points and lines of ankle surface. Table 1 depicts statistical analysis of characteristic distances for 105 participants, while Table 2 describes statistical analysis for males and females.

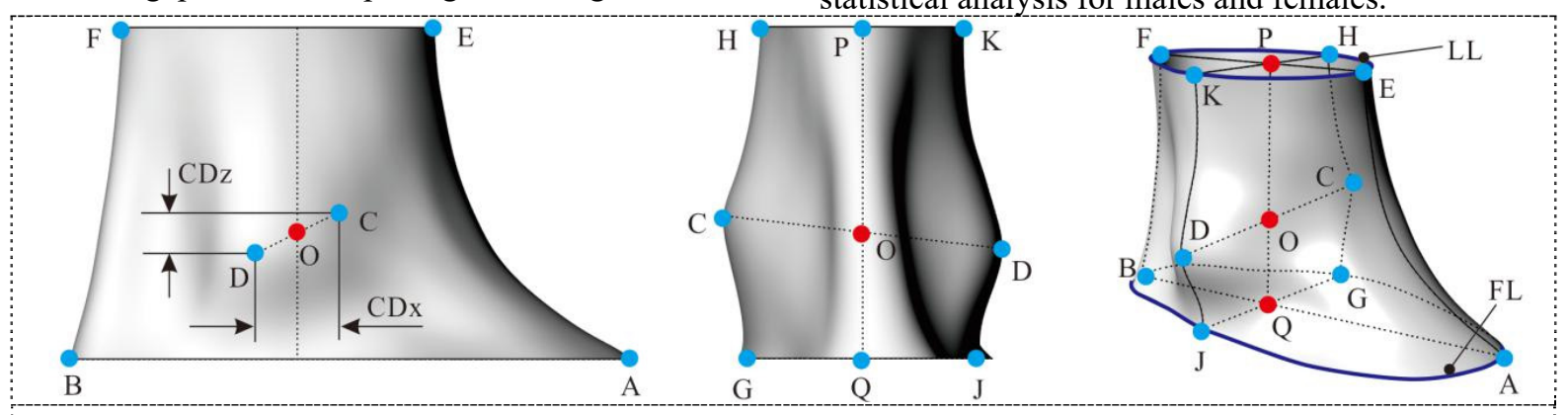

Figure 1. The characteristic points and lines of ankle.

Table 1. Describe statistical analysis for 105 participants (mm).

\begin{tabular}{ccccccccccccc}
\hline & AB & GJ & FL & EF & HK & LL & CD & CDz & CDx & PQ & OQ & BQ \\
\hline Mean & 125.3 & 56.6 & 303.9 & 76.7 & 62.4 & 209.8 & 70.0 & 11.2 & 10.1 & 67.6 & 25.8 & 55.3 \\
Max. & 140.4 & 73.9 & 342.4 & 94.3 & 79.5 & 267.8 & 81.7 & 22.5 & 18.8 & 83.8 & 36.8 & 67.5 \\
Min. & 106.1 & 47.1 & 257.7 & 66.7 & 52.3 & 182.7 & 58.4 & 2.8 & 5.0 & 49.5 & 18.3 & 42.0 \\
SD & 8.59 & 4.78 & 19.51 & 5.15 & 4.65 & 15.45 & 4.85 & 4.23 & 2.61 & 8.91 & 3.76 & 5.05 \\
\hline
\end{tabular}

Table 2. Describe statistical analysis for males and females (mm).

\begin{tabular}{cccccccccccccc}
\hline & & AB & GJ & FL & EF & HK & LL & CD & CDz & CDx & PQ & OQ & BQ \\
\hline \multirow{2}{*}{ Mean } & Male & 130.9 & 58.0 & 317.2 & 78.8 & 65.1 & 215.3 & 73.5 & 12.7 & 10.8 & 73.9 & 27.5 & 57.7 \\
& Female & 119.9 & 55.2 & 291.0 & 74.7 & 59.8 & 204.3 & 66.6 & 9.7 & 9.4 & 61.5 & 24.2 & 52.9 \\
Max. & Male & 140.4 & 73.9 & 342.4 & 94.3 & 79.5 & 267.8 & 81.7 & 22.5 & 17.6 & 83.8 & 36.8 & 67.5 \\
& Female & 135.5 & 64.5 & 330.5 & 85.8 & 70.1 & 229.4 & 76.1 & 21.1 & 18.8 & 75.4 & 31.4 & 63.3 \\
Min. & Male & 113.5 & 47.1 & 281.0 & 69.2 & 59.2 & 182.7 & 64.9 & 4.6 & 6.4 & 55.5 & 19.5 & 49.4 \\
& Female & 106.1 & 49.1 & 257.7 & 66.7 & 52.3 & 187.1 & 58.4 & 2.8 & 5.0 & 49.5 & 18.3 & 42.0 \\
SD & Male & 6.46 & 5.56 & 13.93 & 5.70 & 4.06 & 18.05 & 3.29 & 3.92 & 2.40 & 6.50 & 3.70 & 3.95 \\
& Female & 6.82 & 3.41 & 14.99 & 3.61 & 3.63 & 9.83 & 3.47 & 4.03 & 2.63 & 6.37 & 3.03 & 4.92 \\
\hline
\end{tabular}




\section{Morphological changes and classification}

\subsection{The morphological division and the features of dynamic change}

In order to discuss the characteristics of change of ankle during plantar flexion and dorsiflexion, the morphology is divided into four parts. The part AEKJ is the anterolateral area, denoted as I, the part JKFB as the posterolateral area II, BFHG as the posteromedial area III, and GHEA as the anteromedial area IV. The change of morphology is mainly attributed to the ankle caused by ankle joint and the contraction of relevant muscles in foot and leg. From the appearance, the skin of the ankle expands or contracts, the area changes and the wrapping morphology changes. The four parts change dramatically when the ankle joint extends or flexes.

Table 3 lists the mean areas of the four parts (I, II, III and IV) in three states. Part I (AEKJ) contracts when dorsiflexion and expands when plantar flexion. The ratios of the area in dorsiflexion state $\left(6258 \mathrm{~mm}^{2}\right)$ and plantar flexion state $\left(7675 \mathrm{~mm}^{2}\right)$ to standing state $\left(6422 \mathrm{~mm}^{2}\right)$ are 0.97 and 1.20 respectively. The ratio of area from dorsiflexion to plantar flexion is 0.82 . Namely, the plantar flexion area is 1.23 times as large as the dorsiflexion. Part II (JKFB) expands when dorsiflexion and contracts when plantar flexion. The ratios of the area in dorsiflexion state $\left(4370 \mathrm{~mm}^{2}\right)$ and plantar flexion state $\left(3040 \mathrm{~mm}^{2}\right)$ to standing state $\left(3708 \mathrm{~mm}^{2}\right)$ are 1.18 and 0.82 . The ratio of area from dorsiflexion to plantar flexion is 1.44. Part III (BFHG) is the same as Area II, that is, it expands when dorsiflexion and contracts when plantar flexion. The ratios of the area in dorsiflexion state $\left(6224 \mathrm{~mm}^{2}\right)$ and plantar flexion state $\left(4012 \mathrm{~mm}^{2}\right)$ to standing state $\left(5883 \mathrm{~mm}^{2}\right)$ are 1.06 and 0.68 . The ratio of area from dorsiflexion to plantar flexion is 1.55. Part IV (GHEA) is the same as Area I, that is, it contracts when dorsiflexion and expands when plantar flexion. The ratios of the area in dorsiflexion state $\left(4056 \mathrm{~mm}^{2}\right)$ and plantar flexion state $\left(6365 \mathrm{~mm}^{2}\right)$ to standing state $\left(5122 \mathrm{~mm}^{2}\right)$ are 0.79 and 1.24. Namely, the plantar flexion area is 1.57 times as large as the dorsiflexion.

The anterior and posterior parts had large contraction and expansion during plantar flexion and dorsiflexion motions. The medial and lateral parts of ankle shape were asymmetric, but had equal skin areas. Therefore, the area of the entire ankle surface remained almost the same when morphological changes.

Table 3. Mean areas of the four parts $\left(\mathrm{mm}^{2}\right)$.

\begin{tabular}{cccccc}
\hline & I $($ AEKJ $)$ & II $($ JKFB $)$ & III $($ BFHG $)$ & IV $($ GHEA $)$ & Total \\
\hline $\mathrm{St}(\mathrm{S})$ & 6422 & 3708 & 5883 & 5122 & 21307 \\
$\operatorname{Dt}(\mathrm{S})$ & 6258 & 4370 & 6224 & 4056 & 20917 \\
$\mathrm{Pt}(\mathrm{S})$ & 7675 & 3040 & 4012 & 6365 & 21153 \\
\hline
\end{tabular}

\subsection{Data aligned and standard model}

Because the range of motion of ankle joint changes, even in the same statement, the data should be aligned to classify the ankle shape. Ankle plantar flexion and dorsiflexion are the rotation movement of the foot on the sagittal plane with a center point. The point $\operatorname{Df}(\mathrm{A})$ is the point $\mathrm{A}$ in dorsiflexion of ankle and point $\operatorname{Pf}(\mathrm{A})$ as the plantar flexion, the same of points $\mathrm{Df}(\mathrm{B})$ and $\mathrm{Pf}(\mathrm{B})$. The intersection point $\mathrm{O}^{\prime}$ of the perpendicular bisector of line $\operatorname{Df}(\mathrm{A}) \operatorname{Pf}(\mathrm{A})$ and $\operatorname{Df}(\mathrm{B}) \operatorname{Pf}(\mathrm{B})$ is the the rotation center of the foot (figure 2). With $\mathrm{O}^{\prime}$ as the center, rotate the data of the girth FL parallel to the plane of the girth LL, mark characteristic point $\mathrm{A}$ as $\mathrm{Ls}(\mathrm{A})$ and characteristic point $\mathrm{B}$ as $\operatorname{Ls}(\mathrm{B})$ in this state. For all 105 samples, we use the same method so as to unify the dynamic morphological model of ankle. The standard model can be constructed.

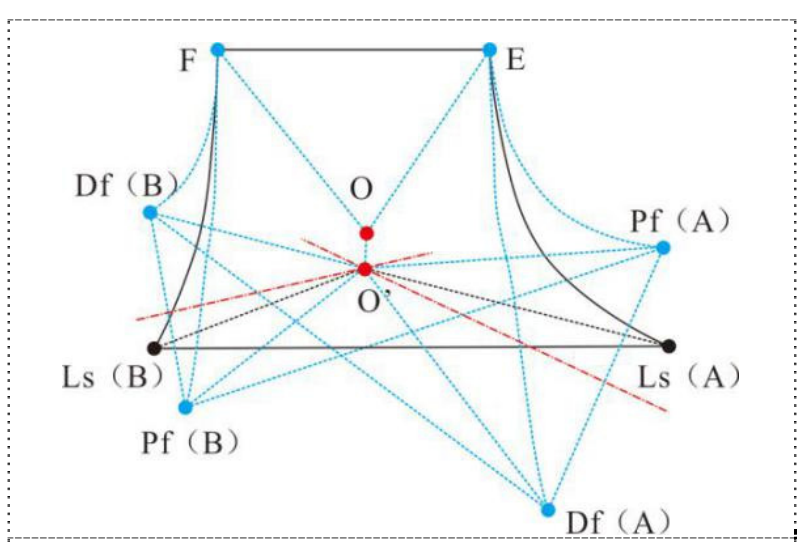

Figure 2. Data aligned.

\subsection{Shape classification}

Pearson's test method was used to detect the main dimensions of ankle in pairs. The results showed that there were significant linear correlation between $\mathrm{AB}, \mathrm{GJ}$, and FL $(r>0.90)$, significant linear correlation between $\mathrm{EF}, \mathrm{HK}$, and LL $(\mathrm{r}>0.90)$, and significant linear correlation between OP and PQ $(r>0.90)$. Points $C$ and $\mathrm{D}$ are two prominent points of ankle shape, which should be classified as characteristics, but there is a certain linear correlation between $\mathrm{CD}$ and $\mathrm{AB}(\mathrm{r}=0.494)$, and between $C D$ and $E F(r=0.452)$. At the same time, we 
test the relationship between $\mathrm{QB}$ and $\mathrm{AB}(\mathrm{r}=0.631)$ which shows that there is also a certain linear correlation. This means the position of point $\mathrm{O}$ on the $\mathrm{x}$-axis is related to the distance of $\mathrm{AB}$. Based on the above discussion, we classify the ankle height PQ (included OP), leg distance EF (included HK and LL) and foot distance $\mathrm{AB}$ (included GJ and FL) as three types, and then separately discuss the location of $\mathrm{C}$ and $\mathrm{D}$ (position of point $\mathrm{O}$ ) and the distribution of dimension $\mathrm{CD}$. According to the ankle height $\mathrm{PQ}$, it can be divided into three type ranges of I, II, and III $(49.5 \mathrm{~mm} \leq \mathrm{I} \leq 60.9 \mathrm{~mm}$, $60.9 \mathrm{~mm}<$ II $\leq 72.4 \mathrm{~mm}$, and $72.4 \mathrm{~mm}<$ III $\leq 83.8 \mathrm{~mm})$, representing the types of ankle height. According to the length $\mathrm{AB}$, it can be divided into $\mathrm{S}, \mathrm{M}$, and $\mathrm{L}(106.1 \mathrm{~mm}$ $\leq \mathrm{S} \leq 117.5 \mathrm{~mm}, 117.5 \mathrm{~mm}<\mathrm{M} \leq 129.0 \mathrm{~mm}$, and $129.0 \mathrm{~mm}<\mathrm{L} \leq 140.4 \mathrm{~mm}$ ), representing the three types divided by the foot size, and with the length $\mathrm{EF}$, it can be divided into (1), (2), and (3) ( $66.7 \mathrm{~mm} \leq$ (1) $\leq$ $75.9 \mathrm{~mm}, 75.9 \mathrm{~mm}<2 \leq 85.1 \mathrm{~mm}$, and $85.1 \mathrm{~mm}<$ (3) $\leq$ $94.3 \mathrm{~mm}$ ), representing three types divided by leg size.

To display the classification form more intuitively, all points are converted to the coordinate system with B as

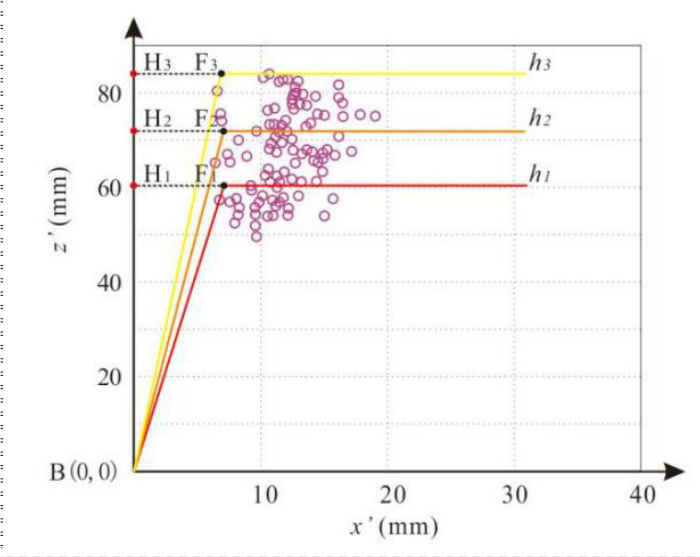

Figure 3. Distribution of point $F$.

In fact, not all groups mentioned above exist, so we map 105 groups of data obtained from actual scanning to 27 groups, and observe the distribution of each group. As shown in the table 4 , there are actually 17 groups. It can be seen from the actual groups that type III and type (3) in type $\mathrm{S}$ are absence, namely, there is no group with very small foot girth length, while ankle height and leg girth length are very large. This indicates that foot girth length is small, and ankle height and leg girth length are not too large. In type $\mathrm{L}$, there may be various leg dimension and ankle height with large foot girth length. In type (3), only $\mathrm{I}(\mathrm{L}) \cup(3), \mathrm{II}(\mathrm{L}) \cup(3)$, and $\mathrm{III}(\mathrm{L}) \cup(3)$ exist, indicating that the leg dimension is large, and the the origin $(0,0,0)$, and BA direction is $x^{\prime}$ axis. The distribution of point $\mathrm{F}$ (figure. 3 ) on the boundary of types I, II, and III is obtained by the following methods: (1) $\mathrm{H}_{1}$ $(0,0,60.9), \mathrm{H}_{2}(0,0,72.4)$, and $\mathrm{H}_{3}(0,0,83.8)$ are taken on the $\mathrm{z}$-axis, and the horizontal lines $\mathrm{h}_{1}, \mathrm{~h}_{2}$ and $\mathrm{h}_{3}$ are made respectively. (2) Draw lines from characteristic point $B$ to all characteristic points F. (3) Find lines BF with minimum angle from positive $\mathrm{z}$-axes in each group of I, II, and III. (4) Extend BF to intersect with $\mathrm{h}_{1}, \mathrm{~h}_{2}$ and $\mathrm{h}_{3}$. The intersecting points $\mathrm{F}_{1}, \mathrm{~F}_{2}$ and $\mathrm{F}_{3}$ would be the boundary location of each group, as shown in the figure. For point $\mathrm{A}$, taking $\mathrm{A}_{1}, \mathrm{~A}_{2}$, and $\mathrm{A}_{3}$ respectively according to the upper limit of three ranges of $\mathrm{AB}$, there are $\mathrm{BA}_{1}=$ $117.5 \mathrm{~mm}, \mathrm{BA}_{2}=129.0 \mathrm{~mm}, \mathrm{BA}_{3}=140.4 \mathrm{~mm}$. Point $\mathrm{E}$ is distributed on $h_{1}, h_{2}$ and $h_{3}$ according to the height types. At the same time, with the three value ranges of length EF types, there are 9 limit position points in total. Take points $\mathrm{E}_{1}, \mathrm{E}_{2}$, and $\mathrm{E}_{3}$ on $\mathrm{h}_{1}, \mathrm{E}_{4}, \mathrm{E}_{5}$, and $\mathrm{E}_{6}$ on $\mathrm{h}_{2}, \mathrm{E}_{7}, \mathrm{E}_{8}$, and $E_{9}$ on $h_{3}$, then the length $F_{1} E_{1}=F_{1} E_{2}=F_{1} E_{3}=$ $75.9 \mathrm{~mm}, \mathrm{~F}_{2} \mathrm{E}_{4}=\mathrm{F}_{2} \mathrm{E}_{5}=\mathrm{F}_{2} \mathrm{E}_{6}=85.1 \mathrm{~mm}, \mathrm{~F}_{3} \mathrm{E}_{7}=\mathrm{F}_{3} \mathrm{E}_{8}=$ $\mathrm{F}_{3} \mathrm{E}_{9}=94.3 \mathrm{~mm}$, as shown in the figure 4 . In this way, ankle shape is specifically divided into 27 groups.

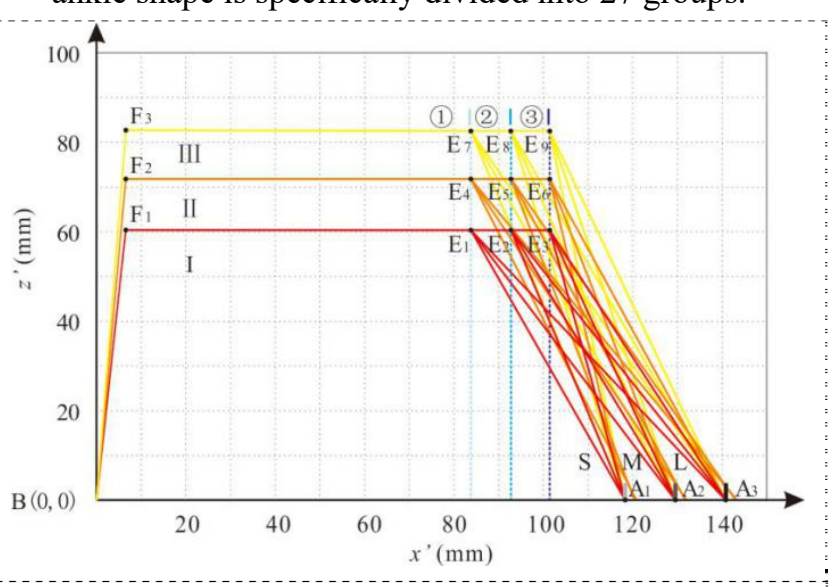

Figure 4. Groups.

foot dimension must be large. In type (1), if the leg dimension is small, there may be various foot dimension types and ankle height. Nearly $16 \%$ of the small and short ones represented by groups $\mathrm{I}(\mathrm{S}) \cup(1)$ and $\mathrm{I}(\mathrm{S}) \cup(2)$ were mainly female, and $14 \%$ of the large and high ones represented by groups $\operatorname{III}(\mathrm{L}) \cup(2)$ and $\mathrm{III}(\mathrm{L}) \cup(3)$ were male.

Table 4. Shape classification.

\begin{tabular}{lll}
\hline $\mathrm{I}(\mathrm{S}) \cup(1)$ & $\mathrm{II}(\mathrm{S}) \cup(1)$ & $\mathrm{III}(\mathrm{S}) \cup(1)$ \\
$\mathrm{M}, \mathrm{F}, \mathrm{P}$ & $\mathrm{M}, \mathrm{F}, \mathrm{P}$ \\
$0,10,9.5 \%$ & $1,3,3.8 \%$
\end{tabular}




\begin{tabular}{|c|c|c|c|}
\hline $\mathrm{I}(\mathrm{S}) \cup(2)$ & $\mathrm{II}(\mathrm{S}) \cup(2)$ & $\mathrm{III}(\mathrm{S}) \cup(2)$ & \\
\hline $\begin{array}{c}\mathrm{M}, \mathrm{F}, \mathrm{P} \\
0,7,6.7 \%\end{array}$ & $\begin{array}{c}\mathrm{M}, \mathrm{F}, \mathrm{P} \\
0,2,1.9 \%\end{array}$ & NO & \\
\hline $\mathrm{I}(\mathrm{S}) \cup(3)$ & $\mathrm{II}(\mathrm{S}) \cup(3)$ & $\mathrm{III}(\mathrm{S}) \cup(3)$ & \\
\hline $\mathrm{NO}$ & $\longrightarrow$ & - & $\longrightarrow$ \\
\hline $\mathrm{I}(\mathrm{M}) \cup(1)$ & $\mathrm{II}(\mathrm{M}) \cup(1)$ & $\mathrm{III}(\mathrm{M}) \cup$ (1) & \\
\hline $\begin{array}{c}\mathrm{M}, \mathrm{F}, \mathrm{P} \\
0,5,4.7 \%\end{array}$ & $\begin{array}{c}\text { M, F, P } \\
2,12,13.3 \%\end{array}$ & $\begin{array}{c}\text { M, F, P } \\
6,1,6.7 \%\end{array}$ & \\
\hline $\mathrm{I}(\mathrm{M}) \cup(2)$ & $\mathrm{II}(\mathrm{M}) \cup(2)$ & $\mathrm{III}(\mathrm{M}) \cup(2)$ & \\
\hline $\begin{array}{c}\mathrm{M}, \mathrm{F}, \mathrm{P} \\
0,4,3.8 \%\end{array}$ & $\begin{array}{c}M, F, P \\
3,4,6.7 \%\end{array}$ & $\begin{array}{c}\mathrm{M}, \mathrm{F}, \mathrm{P} \\
3,0,2.9 \%\end{array}$ & \\
\hline $\mathrm{I}(\mathrm{M}) \cup(3)$ & $\mathrm{II}(\mathrm{M}) \cup(3)$ & $\mathrm{III}(\mathrm{M}) \cup(3)$ & \\
\hline $\mathrm{NO}$ & - & $\longrightarrow$ & 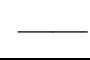 \\
\hline $\mathrm{I}(\mathrm{L}) \cup(1)$ & $\mathrm{II}(\mathrm{L}) \cup(1)$ & $\mathrm{III}(\mathrm{L}) \cup(1)$ & \\
\hline NO & $\begin{array}{l}\mathrm{M}, \mathrm{F}, \mathrm{P} \\
0,1,1 \%\end{array}$ & $\begin{array}{c}\text { M, F, P } \\
9,2,10.5 \%\end{array}$ & \\
\hline $\mathrm{I}(\mathrm{L}) \cup(2)$ & $\mathrm{II}(\mathrm{L}) \cup(2)$ & $\mathrm{III}(\mathrm{L}) \cup(2)$ & \\
\hline NO & $\begin{array}{c}\text { M, F, P } \\
8,1,8.6 \%\end{array}$ & $\begin{array}{c}\mathrm{M}, \mathrm{F}, \mathrm{P} \\
12,0,11.4 \%\end{array}$ & \\
\hline $\mathrm{I}(\mathrm{L}) \cup(3)$ & $\mathrm{II}(\mathrm{L}) \cup(3)$ & $\mathrm{III}(\mathrm{L}) \cup(3)$ & \\
\hline $\begin{array}{c}\mathrm{M}, \mathrm{F}, \mathrm{P} \\
2,0,1.9 \%\end{array}$ & $\begin{array}{c}\mathrm{M}, \mathrm{F}, \mathrm{P} \\
3,1,3.8 \%\end{array}$ & $\begin{array}{c}\mathrm{M}, \mathrm{F}, \mathrm{P} \\
3,0,2.9 \%\end{array}$ & \\
\hline
\end{tabular}

\subsection{Distribution of the medial and lateral ankle protrusion}

We checked out the data of distance of the medial and lateral ankle protrusion (CD). The distribution of the values corresponding to the 17 groups mentioned above is shown in the table 5. In each specific group, the distribution span of CD is large. In terms of the overall distribution, the larger values of the corresponding EF, the greater of the overall $\mathrm{CD}_{\text {mean }}$ values in the same group divided by $\mathrm{AB}$. For instance, $\mathrm{CD}_{\text {mean }}$ of $\mathrm{I}(\mathrm{S}) \cup(1)$ is $63.4 \mathrm{~mm}$, while $\mathrm{CD}_{\text {mean }}$ of $\mathrm{I}(\mathrm{S}) \cup(2)$ is $65.9 \mathrm{~mm}$. Similarly, in the same group divided by EF, the larger values the corresponding $\mathrm{AB}$ are, the greater overall $\mathrm{CD}_{\text {mean }}$ values will be. For example, the $\mathrm{CD}_{\text {mean }}$ of $\mathrm{I}(\mathrm{S}) \cup$ (2) is $65.9 \mathrm{~mm}$, while that of $\mathrm{I}(\mathrm{M}) \cup(2)$ is $69.2 \mathrm{~mm}$. That is to say, $\mathrm{CD}$ is affected by $\mathrm{AB}$ and $\mathrm{EF}$ simultaneously. Because the upper limit value of most product design parameters is considered, the maximum distance of $C D$ in each group can be taken as a reference.

Table 5. The distribution of distance $\mathrm{CD}(\mathrm{mm})$.

\begin{tabular}{cccccccccccc}
\hline Groups & $\mathrm{CD}_{\min }$ & $\mathrm{CD}_{\max }$ & $\mathrm{CD}_{\text {mean }}$ & Groups & $\mathrm{CD}_{\min }$ & $\mathrm{CD}_{\max }$ & $\mathrm{CD}_{\text {mean }}$ & Groups & $\mathrm{CD}_{\min }$ & $\mathrm{CD}_{\max }$ & $\mathrm{CD}_{\text {mean }}$ \\
\hline $\mathrm{I}(\mathrm{S}) \cup(1)$ & 58.4 & 69.6 & 63.4 & $\mathrm{II}(\mathrm{S}) \cup(1)$ & 60.6 & 70.0 & 67.1 & $\mathrm{III}(\mathrm{S}) \cup(1)$ & $\backslash$ & $\backslash$ & $\backslash$ \\
$\mathrm{I}(\mathrm{S}) \cup(2)$ & 62.2 & 70.6 & 65.9 & $\mathrm{II}(\mathrm{S}) \cup(2)$ & 68.5 & 73.2 & 70.8 & $\mathrm{III}(\mathrm{S}) \cup(2)$ & $\backslash$ & $\backslash$ & $\backslash$ \\
$\mathrm{I}(\mathrm{S}) \cup(3)$ & $\backslash$ & $\backslash$ & $\backslash$ & $\mathrm{II}(\mathrm{S}) \cup(3)$ & $\backslash$ & $\backslash$ & $\backslash$ & $\mathrm{III}(\mathrm{S}) \cup(3)$ & $\backslash$ & $\backslash$ & $\backslash$
\end{tabular}




\begin{tabular}{cccccccccccc}
$\mathrm{I}(\mathrm{M}) \cup(1)$ & 63.4 & 71.6 & 66.9 & $\mathrm{II}(\mathrm{M}) \cup(1)$ & 63.6 & 73.7 & 67.4 & $\mathrm{III}(\mathrm{M}) \cup$ & 67.8 & 78.8 & 70.7 \\
$\mathrm{I}(\mathrm{M}) \cup(2)$ & 66.6 & 71.3 & 69.2 & $\mathrm{II}(\mathrm{M}) \cup(2)$ & 64.5 & 76.1 & 70.4 & $\mathrm{III}(\mathrm{M}) \cup$ & 71.5 & 75.6 & 73.7 \\
$\mathrm{I}(\mathrm{M}) \cup(3)$ & $\backslash$ & $\backslash$ & $\backslash$ & $\mathrm{II}(\mathrm{M}) \cup(3)$ & $\backslash$ & $\backslash$ & $\backslash$ & $\mathrm{III}(\mathrm{M}) \cup$ & $\backslash$ & $\backslash$ & $\backslash$ \\
$\mathrm{I}(\mathrm{L}) \cup(1)$ & $\backslash$ & $\backslash$ & $\backslash$ & $\mathrm{II}(\mathrm{L}) \cup(1)$ & 66.6 & 66.6 & 66.6 & $\begin{array}{c}\mathrm{III}(\mathrm{L}) \cup \\
(1)\end{array}$ & 65.7 & 75.6 & 71.5 \\
$\mathrm{I}(\mathrm{L}) \cup(2)$ & $\backslash$ & $\backslash$ & $\backslash$ & $\mathrm{II}(\mathrm{L}) \cup(2)$ & 70.0 & 77.7 & 73.4 & $\mathrm{III}(\mathrm{L}) \cup$ & 70.8 & 77.1 & 73.6 \\
$\mathrm{I}(\mathrm{L}) \cup(3)$ & 69.5 & 81.7 & 75.6 & $\mathrm{II}(\mathrm{L}) \cup(3)$ & 73.9 & 81.3 & 78.1 & $\mathrm{III}(\mathrm{L}) \cup$ & 74.0 & 77.2 & 75.8 \\
\hline
\end{tabular}

\section{Matching design and comfort evaluation of ankle brace}

The products related to ankle, such as ankle braces, ankle boot, and boots, should be matched the ankle morphological changes and groups, so as to meet users' physiological needs. The rigid ankle brace mainly limits the ankle joint. The movement in the direction of extension and flexion needs to be flexible, and its shape design forms are various. But it cannot deviate from the ankle shape changes and varies dimensions. This study carries out design of living example, and tests its comfort through user experience evaluation.

\subsection{Factors of rigid ankle brace fit design}

(1) The brace design match to the morphological changes of anterior and posterior ankle

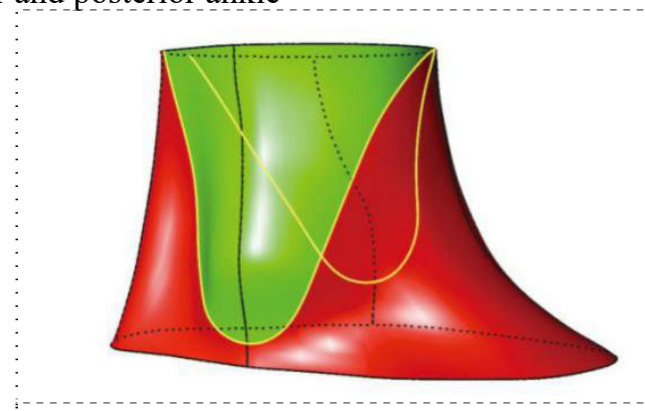

Figure 5. Area of deformed skin surface.

(3) The brace design match to the ankle groups

Wide ranges of ankle dimensions determine the product with the diversity of sizes. For ankle braces design, the purpose of meeting the comfort needs of mass users and matching the shape of products and ankle as much as possible. That is very important to combine the shape classification of ankle.

\subsection{Rigid brace design}

According to the specific usage and function of ankle brace, we design a rigid ankle brace according to the dimensions of group $\mathrm{II}(\mathrm{M}) \cup(1)$ which has a large proportion of relative number of samples. The brace consists of the medial rigid part, the lateral rigid part, the
The design of a brace must give priority to the contraction and expansion deformations of anterior and posterior parts of the ankle. Through the calculation of the distance between two corresponding points on surface in each part, a boundary curve is obtained. This curve determined the specific deformed surface of skin. As shown in figure 5, the yellow curve divided the standard model into deformed skin surface (red) and nondeformed skin surface (green). The design of a brace should consider the deformed surface to match it.

(2) The brace design match to the asymmetry of medial and lateral ankle

As shown in figure 6 , in standing state, we make surfaces AEK'J' and J'K'FB that are symmetric with parts AEKJ and JKFB along the plane ABEF. The differences in position between $C$ and $D^{\prime}$ represented the asymmetry of medial and lateral ankle. They are the height difference of $10.1 \mathrm{~mm}$ and anteroposterior difference of $11.3 \mathrm{~mm}$ respectively.

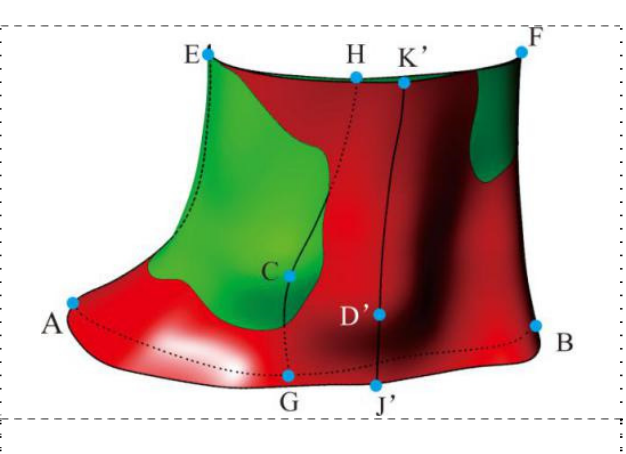

Figure 6. Surfaces AEK'J' and J'K'FB.

foot area rigid part, the elastic material part, and the connecting fastener. The foot area rigid part and the elastic material part are taken as a whole. When the brace is used, the medial and the lateral rigid part are connected and fixed by connecting fastener. The appearance size of the brace should be set according to the thickness of rigid material and elastic material. Due to the change of ankle shape, the hollow part of the foot area between the medial and the lateral rigid part ensures the change of the extension and contraction of the ankle shape surface from $20^{\circ}$ dorsiflexion to $50^{\circ}$ plantar flexion. The foot size and classification are not discussed here. The parts and main dimensions are shown in the figure 7 . 


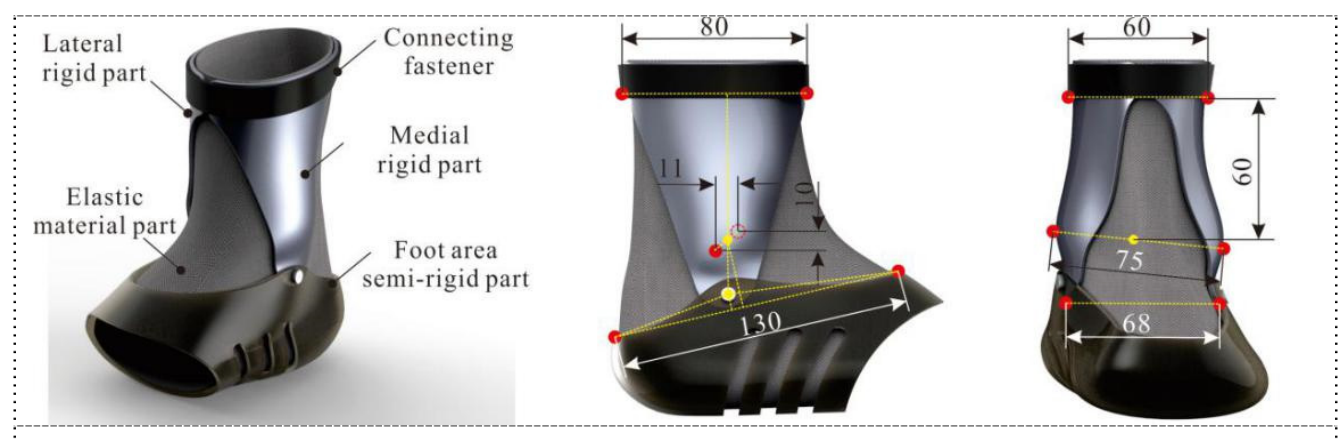

Figure 7. Rigid brace design and the main dimensions.

\subsection{Comfort evaluation}

Comfort is an important indicator of wearable products. The most intuitive evaluation method of comfort is subjective evaluation. In this study, we choose the proper users to wear the designed products of rapid prototyping, and then we evaluate the rigid ankle protection comfort in the following two ways through the user experience.

(1) Likert Scale

There are 10 subjects including 5 people with II(M) $\cup(1)$ and 5 people with other groups of the ankle. Participants put on the designed braces according to the shape classification for more than 1 hour. Movement of walking, running or jumping can be allowed. We use the method of 5-order Likert Scale to judge the comfort effect based on the final score. There are 5 scores (1-5) for comfort, from low to high degree of comfort, and statistical results show that 5 people with II(M) $\cup$ (2) of ankle are 21 scores in total, while people with other groups of ankle is 14 scores.

(2) Interview and comparison

Similarly, we look for 6 people with $\mathrm{II}(\mathrm{M}) \cup(1)$ of ankle, who wear designed product and a similar product on the market at the same time on both left and right feet. The two groups of products are randomly selected for the left and right foot, and the time is more than 1 hour. Do the same action as the first method. By way of inquiry, 4 of them feel that the designed braces has higher comfort degree, while 2 of them feel that there is not much difference between the two products.

\section{Conclusions}

The sample data with flexion and extension states of 105 legs and feet were scanned and unified the morphological model of the ankle. On this basis, (1) the feature of the ankle morphological changes was analyzed by dividing it into four parts. (2) The correlation analysis of ankle characteristic distances was made to establish 27 theoretical ankle shape groups. Through the analysis on data measured, there are actually 17 groups. (3) The percentage of samples in each of groups was counted, it showed that there were differences in ankle shape distribution between men and women, and the characteristic distance of female ankle shape was generally smaller than that of male. (4) The rigid brace design was taken as an example and the methods of
Likert Scale and interview were employed to evaluate the comfort of product design. The result showed that the method of design with the ankle morphological changes and shape groups was proved to be effective for matching the mass users.

\section{Acknowledgments}

We are grateful to the 105 participants in China for their participation.

\section{References}

1. Burdett, Ray, G. (1982) Forces predicted at the ankle during running. Medicine \& Science in Sports \& Exercise, 14: 308-316.

2. Fong, D.T.P., Hong, Y., Chan, L.K., Yung, P.S.H., Chan, K.M. (2007) A Systematic Review on Ankle Injury and Ankle Sprain in Sports. Sports Medicine, 37: 73-94.

3. Abid, H., Mohd, J. (2019) 3D scanning applications in medical field: a literature-based review. Clinical Epidemiology and Global Health, 7: 199-210.

4. Claassen, L., Luedtke, P., Yao, D., Ettinger, S., Daniilidis, K., Nowakowski, A.M., Müller-Gerbl, M., Stukenborg-Colsman, C., Plaass, C. (2017) Ankle morphometry based on computerized tomography. Foot and Ankle Surgery, 23: 121.

5. Yu, J.F., Lee, K.C., Wang, R.H., Chen, Y.S., Fan, C.C., Peng, Y.C., Tu, T.H., Chen, C., Lin, K.Y. (2015) Anthropometry of external auditory canal by non-contactable measurement. Applied Ergonomics, 50: $50-55$.

6. Harih, G., Dolsak, B. (2013) Tool-handle design based on a digital human hand model. International journal of industrial ergonomics, 43: 288-295.

7. Volonghi, P., Baronio, G., Signoroni, A. (2018) 3D scanning and geometry processing techniques for customised hand orthotics: an experimental assessment. Virtual and Physical Prototyping, 13: 112.

8. Ji, X.M., Zhu, Z.H., Gao, Z., Bai, X.B., Hu, G. (2018) Anthropometry and classification of auricular concha for the ergonomic design of earphones. Human Factors and Ergonomics in Manufacturing \& Service Industries, 28: 90-99. 
9. Sun, S.P., Chou, Y.J., Sue, C.C. (2009) Classification and mass production technique for three-quarter shoe insoles using non-weight-bearing plantar shapes. Applied Ergonomics, 40: 630-635.

10. Lee, Y.C., Wang, M.J. (2015) Taiwanese adult foot shape classification using 3D scanning data. Ergonomics, 58: 513-523.

11. Wang, C.S. (2010) An analysis and evaluation of fitness for shoe lasts and human feet. Computers in Industry, 61: 532-540.

12. Baek, S.Y., Lee, K. (2012) Parametric human body shape modeling framework for human-centered product design. Computer Aided Design, 44: 56-67.

13. Irzmańska, M., Okrasa, M. (2018) Evaluation of protective footwear fit for older workers $(60+)$ : a case study using 3D scanning technique. International Journal of Industrial Ergonomics, 67: 27-31. 